\title{
Development and Validation of the Wesleyan Intercultural Competence Scale (WICS): A Tool for Measuring the Impact of Study Abroad Experiences
}

\author{
Steven E. Stemler \\ Wesleyan University
}

Toshie Imada

Brunel University, United Kingdom

\section{Carolyn Sorkin \\ Independent Consultant, USA}

As globalization becomes commonplace and the world becomes increasingly interconnected, institutions of higher education have begun to prioritize the development of intercultural competence in their students. A recent review of university statements of essential learning outcomes revealed that $85 \%$ of top-ranked National Universities in the U.S. and 68\% of top-ranked Liberal Arts colleges in the U.S. stated that the development of intercultural competence is one of their primary objectives (Stemler, 2012). For National Universities this was the most frequently cited objective across the entire sample, edging out other priorities such as writing, quantitative reasoning, and information literacy. The importance of developing the intercultural competence of students has been emphasized by private-sector businesses as well. A 2010 study commissioned by the Association of American Colleges and Universities found that $67 \%$ of the 302 employers interviewed felt that the ability to understand the global context of situations and decisions was one of the most important aims of higher education (AAC\&U, 2010).

Despite the relative consensus that exists regarding the importance of developing intercultural competence, scholars vary greatly in how they define or even name the construct (Deardorff, 2009; Spitzberg \& Changnon, 2009). Different terms found in the literature include intercultural communication competence, transcultural communication, cross-cultural adaptation, intercultural literacy, multiculturalism, and intercultural sensitivity, among others (Fantini, 2006; Sinicrope, Norris, \& Watanabe, 2007). The term culture itself has been defined in a wide variety of ways by different scholars. ${ }^{1}$ However, culture generally refers to the history, attitudes, values, traditions,

\footnotetext{
${ }^{1}$ Culture does not necessarily equate to "nationality", although this is a common way the term is used.
} There are various ethnic groups within a nation as well as different subcultures that may have little or nothing to do with nationality. For example, different social groups, such as "jocks", "hippies", "hipsters", "techies", etc. may each represent their own subculture within the context of a college campus. One reasonably may 
beliefs, organization, and behaviors communicated by individuals from one generation to the next via language or some other means (Sternberg, 2004). Some researchers, such as Hirsch (1987), have conceptualized intercultural competence as consisting of a particular body of knowledge. Other researchers, such as Caligiuri, Jacobs, and Farr (2000), have conceptualized intercultural competence as consisting mainly of attitudes and behaviors. Although each of these terms and conceptualizations are slightly different from one another, most scholars agree that at least the following broad elements are characteristic of an individual with a high degree of intercultural competence: knowledge (e.g., cultural knowledge, self-awareness), attitudes (e.g., openness, respect, valuing others), and skills (e.g., listening, analyzing, language) (Byram, 1997; Deardorff, 2006; Spitzberg \& Changnon, 2009; TingToomey \& Kurogi, 1998).

It should be noted that although there is consensus with regard to these broad elements (knowledge, attitudes, and skills), there is less agreement on the specific components of each of these elements (Deardorff, 2006). Nevertheless, in her Delphi study of intercultural scholars, Deardorff found that, "Of the specific components of intercultural competence noted, many of them addressed an individual's personal attributes, such as curiosity, general openness, and respect for other cultures." (p. 248). In addition, cross-cultural empathy and the ability to tolerate and engage ambiguity were endorsed by most scholars as key characteristics of interculturally-competent individuals. Further, all scholars agreed that interculturally-competent individuals should show an understanding of others' world views.

\section{Theoretical Framework}

Perhaps one of the most widely accepted theories of intercultural competence is that of Bennett (1986). According to Bennett's Developmental Model of Intercultural Sensitivity (DMIS), individuals can be located along a developmental trajectory in one of six stages that indicate their worldviews and response to cultural differences. The first three stages (Denial, Defense, Minimization) relate to ethnocentrism while the last three (Acceptance, Adaptation, Integration) relate to ethnorelativism.

In the denial stage, individuals recognize fairly obvious cultural differences such as food and dress, but fail to notice the existence of deeper structural differences between cultures and may avoid or withdraw from cultural differences. In the defense stage individuals react against the threat of other cultures by denigrating those cultures and promoting the superiority of their own culture. In the minimization stage, individuals consider all cultures to be fundamentally similar because they focus on universal values and principles that apply across cultures without fully considering and appreciating other deep structural differences that are culture-specific. Moving up the developmental ladder to ethnorelativism, the next stage is acceptance. In this stage, individuals accept and respect

argue that developing "intercultural competence" means developing the kinds of skills that would allow one successfully to navigate communications across each of these different subgroups. We are aware that "nationality" might ignore the differences among such subgroups. However, as the focus of the present research is to investigate the effect of study-abroad experience, we shall limit our treatment of culture to that provincial meaning of "nationality." 
cultural differences with regard to behavior and values. In the adaptation stage, individuals develop the ability to shift their frame of reference to culturally diverse worldviews through empathy and pluralism. Finally, in the highest stage of development, that of integration, individuals expand and incorporate other worldviews into their own worldview. Empirical studies have supported the validity of Bennett's DMIS (Hammer, Bennett, \& Wiseman, 2003; Hammer, 2011; Paige, JacobsCassuto, Yershova, \& DeJaeghere, 2003). As a result, Bennett's DMIS was used as the guiding theoretical framework in the current study.

\section{The Development of Intercultural Competence}

If intercultural competence develops in stages, the next relevant question of interest within the context of higher education is how best to facilitate its development among students. There are several mechanisms by which universities attempt to facilitate the development of their students' intercultural competence. One approach has been to focus on the curriculum. For example, the movement in higher education toward internationalizing the curriculum involves offering a range of courses with international/intercultural elements (Bond, 2006; Burn, 2002; Edwards \& Tonkin, 1990; Green \& Olson, 2003; Nilsson, 2000; Schapper, \& Mayson, 2004; Schuerholz-Lehr, Caws, van Gyn, \& Preece, 2007).

Another mechanism by which universities attempt to facilitate the development of intercultural competence is by admitting international students to the university. Gürüz (2011) has pointed out that universities today are educating a larger number of international students than ever before. Indeed, the skills that many institutions value so highly, such as the development of cultural competence, citizenship, and ethical reasoning are only partly developed within the context of formal instruction. As large-scale survey research, longitudinal studies, and experimental research have shown, when students are immersed in a diverse student body, it has positive effects on a wide variety of learning outcomes, retention, satisfaction, leadership skills, and civic engagement. For example, reporting on the results of the National Survey of Student Engagement (NSSE), which includes data from more than 285,000 students nationwide, Kuh (2003) found that students were more likely to be involved in active and collaborative learning when they were exposed to greater diversity, and they were more likely to report being satisfied with the college experience. From an experimental perspective, Antonio, Chang, Kenny, Levin, and Milem (2003) found that students who were randomly assigned to groups with greater ethnic diversity showed more complex thinking, as measured by pre- and post-discussion essays. Further, in an analysis of longitudinal data from a nationally representative sample of 4,200 students, Hurtado (2001) found that studying with peers from diverse backgrounds had a more pronounced impact on self-reported growth in thinking and problem-solving skills than a curriculum emphasizing different perspectives did. Thus, exposure to individuals from a diverse range of backgrounds appears to add a value far greater than simply studying about diversity.

A third mechanism, which is the focus of the current study, is to offer students the opportunity to study abroad. Historically speaking, sending students to study abroad has been seen as critical in the process of helping U.S. citizens develop a more international mindset in the post-World War I era (Hoffa, 2010). More recently, in the wake of the September 11, 2001 terrorist attacks on the 
United States, the American Council on Education issued a report calling for an increased emphasis on developing the intercultural competence of students (American Council on Education, 2002). Specifically, the report stated, "Like the challenge of Sputnik in 1957, the attacks of September 11 have brought America's international preparedness to a crossroads. The global transformations of the last decade have created an unparalleled need in the United States for expanded international knowledge and skills. But the nation is unready. And our future success or failure in international endeavors will rely almost entirely on the global competence of our people." (p. 7). At the same time, the rapid rate of globalization has led private-sector businesses to call for colleges to produce interculturally competent graduates (AAC\&U, 2010). Indeed, some researchers have suggested that the greater the exposure to a new culture, the greater the likelihood that students will learn (Lou \& Bosley, 2008; Savicki \& Selby, 2008).

It is perhaps not surprising, then, that the popularity of study abroad programs has been increasing steadily over the past decade. Specifically, the number of American students studying abroad has nearly doubled since the turn of the century, with the total number of U.S. students studying abroad reaching 270,604 in the 2009/2010 academic year (Institute of International Education, 2011). Today, approximately $14 \%$ of U.S. undergraduates study abroad (Fast Facts, 2011).

Although study-abroad programs are presumed to increase the intercultural competence of the participants, research that systematically explores the effectiveness of these programs in accomplishing this aim is just beginning to emerge (Salisbury, 2011). One recent example, the Georgetown Consortium Project (Vande Berg, Connor-Linton, \& Paige, 2009) examined the impact of study abroad upon language development and intercultural competence in a sample of 1,159 students studying abroad in various programs and compared them to 138 students who enrolled in similar courses, but did not study abroad, but rather stayed at one of three U.S. institutions. Using the Intercultural Development Inventory (IDI) (Hammer, 1998; Hammer, Bennett, \& Wiseman, 2003) as their outcome variable, they found that many study-abroad students significantly increased their level of intercultural competence. Further, these findings showed an interaction with gender in which female students made statistically significant gains in intercultural competence while male students did not.

Other large-scale studies, such as the Wabash Study of Liberal Arts Education (Blaich \& Wise, 2011) have some components that are aimed at looking at the impact of study abroad and/or the development of intercultural competence among students (Salisbury, 2011); however, the instruments used to measure the construct are often limited. Indeed, one possible reason that systematic research in this area historically has been lacking may be that there has been some question as to how best to measure and demonstrate objectively the development of intercultural competence within the context of study abroad programs. While many measurement instruments do exist (see Fantani, 2009 for a review), the field has not reached a consensus on the best approach to measuring intercultural competence. 


\section{The Measurement of Intercultural Competence}

One of the reasons so many instruments attempting to measure intercultural competence have been developed is because each reflects a particular definition of the construct. As stated previously, although some researchers are attempting to create a consensus in the field with regard to the definition of intercultural competence (e.g., Deardorff, 2006, 2009), the fact remains that there are many different viewpoints regarding the construct.

In addition, another reason that there are so many different instruments is because within the field of measurement, there are three potential concepts that can be assessed for any given construct: (i) attitudes, (ii) behaviors, or (iii) cognitions (e.g., knowledge). In order to illustrate these different approaches to measurement, we will highlight and discuss one prominent instrument representing each of these broad categories.

One dominant conceptualization is that intercultural competence reflects the mastery of a particular body of knowledge (e.g., Hirsch, 1987). In operating this perspective, Corbitt (1998) has developed a test called the Global Awareness Profile (GAP), which consists of 120 multiple-choice items designed to test cultural knowledge in thirteen areas. The thirteen areas include one general global section, six sections related to geographic knowledge of different regions (e.g., Asia, Africa, North America), and six separate sections dealing with knowledge related to the following broad context areas: (i) environment, (ii) politics, (iii) geography, (iv) religion, (v) socioeconomics, and (vi) culture. Despite its psychometric strengths, the GAP is of limited use in evaluating study abroad experiences because it is a purely knowledge-based test. Thus, one need not have a cultural immersion experience to perform well on the test. Also, knowledge of a particular region may not be particularly relevant to a student studying in a different region, and focus on regions does not address issues occurring trans-regionally. Furthermore, although knowledge is one important aspect of intercultural competence, it is not the only important aspect and may not even be the central element that students are expected to acquire when considering the construct of intercultural competence.

A second popular measure, representing an attempt to measure some of the behavioral aspects of intercultural competence, is the Attitudinal and Behavioral Openness Scale (ABOS) (Caligiuri, et al., 2000). The ABOS is based on the theory that personality characteristics, which are stable, enduring traits, will be the best predictor of successful adaptation in a cross-cultural environment. The ABOS consists of 24 items divided across four subscales designed to measure: (i) attitudes (e.g., other cultures fascinate me), (ii) past experience (e.g., I am fluent in another language), (iii) comfort with differences, (e.g., my friends' ethnic backgrounds are different from mine), and (iv) participation in cultural activities (e.g., I eat at a variety of ethnic restaurants). There is good evidence of construct validity of the instrument for measuring the four stated dimensions. In addition, the ABOS has good criterion-related validity with the personality characteristic of openness to experience, which has been found to relate to intercultural competence (Black, 1990). However, one critique of this conceptualization is that it leaves little room for the possibility that one may develop the necessary cognitive skills or personality characteristics that lead to enhanced intercultural competence. Such assumptions are generally antithetical to one of the primary purposes of study abroad, which is to 
enhance the development of intercultural competence. Given that personality traits are assumed to be relatively stable, one would not expect to see much change to those traits over time.

Finally, one of the most widely used attitudinal tests of intercultural competence, based on Bennett's DMIS, is the Intercultural Development Inventory (IDI) (Hammer, 1998; Hammer, et al., 2003). The IDI consists of 60 general statements to which participants rate their agreement or disagreement on a seven-point scale. Examples of items include, "People should avoid individuals from other cultures who behave differently," and, "Cultural differences are less important than the fact that people have the same needs, interests, and goals in life."

The main advantage of the IDI is that it has a strong theoretical basis that assumes that intercultural competence can be developed over time and experience. It has been used to measure the development of intercultural competence within the context of study abroad (Engle \& Engle, 2004) and it has been shown to have reasonably good psychometric properties (Paige et al., 2003). The IDI suffers from certain limitations, however. Specifically, it is a self-report measure, which increases its susceptibility to faking (van de Mortel, 2008). In addition, it asks abstract attitudinal questions rather than tying each question to a specific context - an approach to questioning that has been shown to relate poorly to actual behavior (DeVellis, 1991). Finally, the IDI is a commercial test and is costly for institutions of higher education to administer and score.

\section{Purpose of the Current Study}

In order to overcome the limitations associated with existing measures of intercultural competence, we developed the Wesleyan Intercultural Competence Scale (WICS). The WICS is based on Bennett's DMIS and uses a situational judgment testing (SJT) approach (McDaniel \& Nguyen, 2001; Weekley \& Ployhart, 2006). The SJT approach links questions to specific situational contexts and aims to assess the behavioral aspect of intercultural competence. The content, construct, and criterion-related validity evidence associated with the WICS are the focus of this study, as well as its utility in capturing change in the development of intercultural competence as a result of study abroad experiences. In addition, we will explore the relationship among intercultural competence, participant demographics (e.g., gender, ethnicity) and specific components of study abroad experiences (e.g., language immersion, situational exposure).

\section{Method}

\section{Participants}

An email inviting students to participate in an online survey related to the assessment of intercultural competence was sent to students participating in study-abroad programs at that time and/or who had just returned from a study-abroad experience between Fall 2010 and Fall 2011.

Demographic information of the participants, including their gender, age, ethnicity, and host countries, is shown in Table 1. 
Table 1. Demographic information of the participants in Part 1 and Part 2

\begin{tabular}{|c|c|c|c|c|c|}
\hline & Gender & $\begin{array}{l}\text { Mean Age } \\
(\mathrm{SD})\end{array}$ & Ethnicity & Nationality & Host Country \\
\hline $\begin{array}{l}\text { Part 1 } \\
(\mathrm{N}=97)\end{array}$ & $\begin{array}{l}\text { Female } 67 \\
\text { Male } 28 \\
\text { Missing } 2\end{array}$ & $\begin{array}{l}20.47 \\
(.78)\end{array}$ & $\begin{array}{l}\text { White } 70 \\
\text { Asian/Asian-American } 9 \\
\text { African-American } 5 \\
\text { Latino } 1 \\
\text { Other/Mixed } 10 \\
\text { Missing } 2\end{array}$ & $\begin{array}{l}\text { U.S. } 88 \\
\text { Other } 6^{a} \\
\text { Missing } 3\end{array}$ & $\begin{array}{l}\text { Argentina } 8 \\
\text { Denmark } 9 \\
\text { Ecuador } 3 \\
\text { France } 11 \\
\text { Germany } 4 \\
\text { Ghana } 2 \\
\text { Greece } 4 \\
\text { India } 4 \\
\text { Italy } 6 \\
\text { Morocco } 2 \\
\text { Peru } 2 \\
\text { South Africa } 3 \\
\text { Spain } 6 \\
\text { Tanzania } 3 \\
\text { UK } 13 \\
\text { Multiple countries } 4 \\
\text { Other } 12^{\text {b }} \\
\text { Missing } 1\end{array}$ \\
\hline $\begin{array}{l}\text { Part 2 } \\
(\mathrm{N}=30)\end{array}$ & $\begin{array}{l}\text { Female } 21 \\
\text { Male } 9\end{array}$ & $\begin{array}{l}20.33 \\
(.71)\end{array}$ & $\begin{array}{l}\text { White } 25 \\
\text { Asian/Asian-American } 2 \\
\text { Latino } 2 \\
\text { African-American } 1\end{array}$ & $\begin{array}{l}\text { U.S. } 28 \\
\text { Other } 2^{c}\end{array}$ & $\begin{array}{l}\text { Denmark } 2 \\
\text { France } 6 \\
\text { Germany } 2 \\
\text { Italy } 2 \\
\text { Spain } 4 \\
\text { UK } 3 \\
\text { Multiple countries } 3 \\
\text { Other } 8^{\mathrm{d}}\end{array}$ \\
\hline
\end{tabular}

a Other included Lithuania, Singapore, Thailand, Philippines, Croatia, and Dominican Republic.

b Other included Australia, Chile, Costa Rica, Czech Republic, Hungary, Jordan, South Korea, Mexico, Nepal, Netherland, Russia, and Samoa.

c Other included Singapore and Thailand.

d Other included Australia, Costa Rica, Greece, Hungary, Japan, South Africa, South Korea, Tanzania.

Ninety-seven undergraduate students at Wesleyan University, who were participating in or had just completed study abroad programs, participated voluntarily in Part 1 (Validity Study) of our online survey. All participants provided informed consent and were compensated with a movie ticket or Amazon gift card for their participation.

Thirty undergraduate students participated in Part 2 of the study (Measuring Change in Intercultural Learning [ICL]), which involved completing the online survey twice - once at the beginning of their study abroad experience and once at the end - to measure changes in their level of intercultural competence. The first response came within their first few weeks of the study abroad program and the second response came at the end of the program. Individuals received a movie ticket or Amazon gift card for participation.

As shown in Table 1, countries in which students studied included the United Kingdom, France, Denmark, Argentina, and many others. Wesleyan University offers University administered and approved programs in over 45 countries around the world. Through consultation with faculty 
members and the Office of International Studies staff, students choose programs that match their interests, goals and qualifications.

\section{Instruments}

Criterion-related validity evidence was gathered by simultaneously administering eight existing measures that evaluate personalities/attitudes. These measures included: openness (International Personality Item Pool [IPIP], 2011), perspective-taking (Davis, 1980), and empathy (Davis, 1980), which are known to be associated with intercultural competence or conceptualized by leading scholars as important elements of intercultural competence (Deardorff, 2006). In addition, we included internationalism (Kosterman \& Feshbach, 1989), nationalism (Kosterman \& Feshbach, 1989), smugness (Kosterman \& Feshbach, 1989), patriotism (Kosterman \& Feshbach, 1989), and ambiguity tolerance (MacDonald, 1970), which were used by Caligiuri, Jacobs, and Farr (2000) for testing the construct validity of their Attitudinal and Behavioral Openness Scale. Each of these measures is described briefly below. For Part 1 (Validation study), all participants completed the WICS, the eight validation measures and a background questionnaire.

Wesleyan Intercultural Competence Scale (WICS). The WICS presents 16 situations that studyabroad students are likely to encounter (e.g., a trip to the grocery store, navigating local transportation See Table 2 for the list of situations and the frequency with which they were encountered by participants in Part 1). Some situations were based on students' real experiences during their study abroad, while others were based on the authors' personal experiences and observations.

Associated with each situation are six different response options designed to reflect the six levels of intercultural competence proposed by Bennett (1986). Participants were asked to rate each response on a scale of 1 (very inaccurate) to 5 (very accurate) to indicate the degree to which each response statement described their actual responses during their most recent experience abroad. If participants had not encountered the situations, they chose "did not encounter such a situation" and skipped the ratings of the responses. Table 3 provides an example of how the items were mapped onto the DMIS (see Appendix A for the complete instrument). 
Steven Stemler, Toshie Imada \& Carolyn Sorkin

Table 2. Numbers of participants who encountered the 16 situations presented in WICS $(\mathrm{N}=97)$

\begin{tabular}{|c|c|c|}
\hline & Situation & Frequency (\%) \\
\hline S13 & When I used local public transportation, & $95(97.9)$ \\
\hline $\mathrm{S} 2$ & When I was interacting with local peers, & $94(96.9)$ \\
\hline S3 & When I went out with others, & $93(95.9)$ \\
\hline S8 & When I went grocery shopping, & $91(93.8)$ \\
\hline S9 & When visiting a local landmark, & $85(87.6)$ \\
\hline S11 & $\begin{array}{l}\text { When I could not find something I needed, which I could usually get easily in the } \\
\text { U.S. , }\end{array}$ & $85(87.6)$ \\
\hline S16 & When I was exposed to local media coverage, & $84(86.6)$ \\
\hline S5 & When a local peer expressed views that were different from my own, & $81(83.5)$ \\
\hline S12 & When I ate a local cuisine that tasted really strange, & $76(78.4)$ \\
\hline S10 & $\begin{array}{l}\text { When a local person did not understand what I said in the local language and } \\
\text { seemed to be a bit frustrated or confused, }\end{array}$ & $64(66.0)$ \\
\hline S15 & When I went to a local cultural event with local peers, & $63(64.9)$ \\
\hline S1 & When I was invited to a formal dinner, & $61(62.9)$ \\
\hline S4 & $\begin{array}{l}\text { When I was interacting with a professor (or a supervisor) in a culture where } \\
\text { respecting someone with higher status was considered to be very important, }\end{array}$ & $61(62.9)$ \\
\hline S6 & $\begin{array}{l}\text { When I participated in discussions with other local peers, and others seemed to } \\
\text { be rather quiet, }\end{array}$ & $49(50.5)$ \\
\hline S7 & When I was invited to a local family party and I was not sure how formal it was, & $46(47.4)$ \\
\hline S14 & $\begin{array}{l}\text { When I went to a religious service or event that differed from my own religious } \\
\text { beliefs, }\end{array}$ & $27(27.8)$ \\
\hline \multicolumn{2}{|c|}{ Average } & $72.2(74.4)$ \\
\hline
\end{tabular}

Table 3. Example WICS item "S8: ('When I went grocery shopping')" mapped onto Bennett's DMIS

\begin{tabular}{|l|l|l|}
\hline Bennett's stage & Description of the stage & Response example \\
\hline Denial & $\begin{array}{l}\text { Individuals deny the existence of other } \\
\text { cultures or the difference between them. }\end{array}$ & $\begin{array}{l}\text { I tried to go shopping with other Americans or } \\
\text { find a store that catered to Americans. }\end{array}$ \\
\hline Defense & $\begin{array}{l}\text { Individuals react against the threat of } \\
\text { other cultures by denigrating the other } \\
\text { cultures and promoting the superiority on } \\
\text { one's own culture. }\end{array}$ & $\begin{array}{l}\text { I just got the things that were usually sold in the } \\
\text { U.S. because I was afraid of wasting money for } \\
\text { something terrible. }\end{array}$ \\
\hline Minimization & $\begin{array}{l}\text { Individuals acknowledge cultural } \\
\text { differences on the surface but consider } \\
\text { all cultures as fundamentally similar. }\end{array}$ & $\begin{array}{l}\text { I found that the stores were pretty much like the } \\
\text { ones in the U.S. , and I did not find any big } \\
\text { differences. Grocery stores are just grocery } \\
\text { stores anywhere. }\end{array}$ \\
\hline Acceptance & $\begin{array}{l}\text { Individuals accept and respect cultural } \\
\text { differences with regard to behavior and } \\
\text { values. }\end{array}$ & $\begin{array}{l}\text { I enjoyed finding things that I never saw in the } \\
\text { U.S. and I was curious about what they were. }\end{array}$ \\
\hline Adaptation & $\begin{array}{l}\text { Individuals develop the ability to shift } \\
\text { their frame of reference to other culturally } \\
\text { pluralism. }\end{array}$ & $\begin{array}{l}\text { I often bought local products that were a little } \\
\text { different from the products I get in the U.S. and I } \\
\text { used them a lot in my everyday living. }\end{array}$ \\
\hline Integration & $\begin{array}{l}\text { Individuals expand and incorporate other } \\
\text { worldviews into their own worldview. }\end{array}$ & $\begin{array}{l}\text { I bought and tried local products and discovered } \\
\text { really good ones. So I became more open- } \\
\text { minded and less restricted by familiarity and } \\
\text { brand names when choosing right products for } \\
\text { myself. }\end{array}$ \\
\hline
\end{tabular}


The WICS score is computed by weighing the developmental stage scores differently using the following formula: WICS Score $=(-2.5 \times$ Denial $)+(-1.5 \times$ Defense $)+(-0.5 \times$ Minimization $)+(0.5 \mathrm{x}$ Acceptance $)+(1.5 \times$ Adaptation $)+(2.5 \times$ Integration $)+18$. The weights are useful for detecting the relative importance an individual places on the responses associated with each of the stages. If an individual were to answer each of the six response options within a situation with the same scale value (for example, giving a rating of 5 for each of the six possible response options in a situation indicating that all six behaviors associated with the situation are characteristic of him/her), then the WICS score for that particular situation would be a " 0 " because the values would cancel each other out and the individual would be thought to fall somewhere in the mid-level of development (e.g., between minimization and acceptance). A similar score would be given if the individual said that none of the behaviors were characteristic of him/her (i.e., giving all six situations a rating of 1). In other words, the weights capture the relative positioning of a given individual and account for the fact that different individuals may use the scale values differently. What really matters is whether an individual states that a particular item in a situation is more or less characteristic of his or her own behavior (e.g., a rating of 4 on an item reflecting the adaptation stage, a rating of 2 on an item reflecting the denial stage, and ratings of $3 \mathrm{~s}$ on all other items would suggest that the individual is actually closer to the adaptation stage than the acceptance stage, using this approach to scoring).

Ultimately, an individual score can be computed for each situation based on the formula stated above. The scores across each of the 16 situations are then added together and the average is taken. This step ensures that individuals who responded to different numbers of situations can be compared fairly (e.g., an individual who responded to only three situations can be compared directly to an individual who responded to twelve situations because we take their average score across the number of situations to which they were exposed). An alternative approach is to create an average stage score for each individual. Thus, if an individual responded to only three situations, s/he will have a denial stage score that is the weighted average of the three scores s/he gave to the items corresponding to denial stage response options for those three situations. The score one can receive on this scale ranges theoretically from -18 to 18 , with higher scores indicating greater intercultural competence. A constant value of 18 is then added to all scores in order to eliminate the possibility of negative WICS scores and make scale interpretation more user-friendly. Thus, the potential scores range from 0 to 36. Table 4 presents a worked example along with guidelines for interpreting WICS scores. 
Table 4. Worked Example of WICS Scoring

\begin{tabular}{|llll|}
\hline & Situation_1 & Situation_2 & Weight \\
Denial & 3 & 5 & -2.5 \\
Defense & 5 & 3 & -1.5 \\
Minimization & 1 & 5 & -0.5 \\
Acceptance & 2 & 4 & 0.5 \\
Adaptation & 4 & 4 & 1.5 \\
Integration & 3 & 3 & 2.5 \\
\hline
\end{tabular}

Example: One individual's raw responses to Situations 1 and 2 multiplied out by the weights $\left(3^{*}-2.5\right)+\left(5^{\star}-1.5\right)+\left(1^{*}-0.5\right)+(2 * 0.5)+\left(4^{\star} 1.5\right)+\left(3^{\star} 2.5\right)=$ $\left(5^{\star}-2.5\right)+\left(3^{\star}-1.5\right)+\left(5^{\star}-0.5\right)+(4 * 0.5)+\left(4^{\star} 1.5\right)+\left(3^{\star} 2.5\right)=\quad$ Weighted Average: $-1-4$ WICS score (average across the 2 situations): $(-1+-4) / 2)=-2.5+18=15.5$

Openness. A short-form of the International Personality Item Pool (Neuroticism Extraversion Openness to Experience [NEO-IPIP]) Openness items (ten items) was used (Goldberg et al., 2006; IPIP, 2012). Participants rated each item on a scale of 1 (very inaccurate) to 5 (very accurate). Example items are: I enjoy hearing new ideas; I tend to vote for conservative political candidates (reversed). This scale has been shown to have a Cronbach alpha $=.82$ and is conceptualized by leading scholars to correlate with intercultural competence (Deardorff, 2006).

Patriotism. The Patriotism scale (12 items) from the Patriotic and Nationalistic Attitude Measure developed by Kosterman and Feshbach (1989) was used. Participants rated each item on a scale of 1 (Strongly Disagree) to 5 (Strongly Agree). Example items were: The fact that I am an American is an important part of my identity; In general, I have very little respect for the American people (reversed). This scale was shown to have a Cronbach alpha $=.73$ and, as predicted, to correlate at $r=.04$, ns with the ABOS in the study by Caligiuri et al. (2000).

Nationalism. The Nationalism scale (seven items) from the Patriotic and Nationalistic Attitude Measure developed by Kosterman and Feshbach (1989) was used. Participants rated each item on a scale of 1 (strongly disagree) to 5 (strongly agree). Example items were: Other countries should try to make their government as much like ours as possible; Generally, the more influence America has on other nations, the better off they are. This scale was shown to have a Cronbach alpha $=.70$ and, contrary to expectations, to correlate at $r=-.04$, ns with the ABOS in the study by Caligiuri et al. (2000).

Internationalism. The Internationalism scale (eight items) from the Patriotic and Nationalistic Attitude Measure developed by Kosterman and Feshbach (1989) was used. Participants rated each item on a scale of 1 (strongly disagree) to 5 (strongly agree). Example items were: The agricultural surpluses of all countries should be shared with the have-nots of the world; The alleviation of poverty in other countries is their problem, not ours (reversed). This scale was shown to have a Cronbach alpha $=.62$ and, as predicted, to correlate at $r=.32, p<.01$ with the ABOS in the study by Caligiuri et al. (2000). 
Smugness. The Smugness scale (four items) is from the Patriotic and Nationalistic Attitude Measure developed by Kosterman and Feshbach (1989) was used. Participants rated each item on a scale of 1 (strongly disagree) to 5 (strongly agree). Example items were: The American flag is the best in the world; I think the American people are the finest in the world. This scale was shown to have a Cronbach alpha $=.67$ and, as predicted, to correlate at $r=-.23, p<.05$ with the ABOS in the study by Caligiuri et al. (2000).

Empathy. The Empathetic concern items (seven items) of the Empathy Questionnaire developed by Davis (1980) were used. Participants rated each item on a scale of 1 (very inaccurate) to 5 (very accurate). Example items are: When I see someone being taken advantage of, I feel kind of protective toward them; Sometimes I don't feel sorry for other people when they are having problems (reversed). This scale has been shown to have a Cronbach alpha values ranging from .68 to .73 and test-retest reliability values ranging from .70 to .72 (Davis, 1980).

Perspective-taking. Perspective-taking items (seven items) of the Empathy Questionnaire developed by Davis (1980) were used. Participants rated each item on a scale of 1 (very inaccurate) to 5 (very accurate). Example items were: Before criticizing somebody, I try to imagine how I would feel if I were in their place; If I'm sure I'm right about something, I don't waste much time listening to other people's arguments (reversed). This scale has been shown to have a Cronbach alpha values ranging from .71 to .75 and test-retest reliability values ranging from .61 to .62 (Davis, 1980).

Ambiguity tolerance. A scale of Ambiguity Tolerance (20 items) developed by MacDonald (1970) was used. Participants responded by choosing either true or false for each item. Example items were: The way to understand a complex problem is to be concerned with their larger aspects instead of breaking them into smaller pieces (receive one point if the response is true); There's a right way and a wrong way to do almost everything (receive one point if the response is false).

Background questionnaire. Participants were asked a variety of questions related to their study abroad placement (e.g., what country they studied in, how they prepared themselves for the study abroad experience, how long they were in the country, how frequently they spoke the language), some demographic questions (e.g., biological sex; ethnicity; age; major; country of origin; whether they had studied, traveled, or lived abroad before), and various self-report questions (e.g., assessment of their own ability to communicate during the past week of their study abroad experience; biggest challenge faced abroad).

\section{Results}

\section{Part 1: Content-related validity evidence}

In order to evaluate the content validity of the test, five undergraduate research assistants not directly involved with the project were recruited as coders. They were provided with a brief description of the six stages of intercultural competence development proposed by Bennett (1986), and then asked to categorize independently each response for each situation into one of the six theoretical stages (denial, defense, etc.). We chose these people as coders because, unlike experts, they did not have prior knowledge of Bennett's Developmental Model of Intercultural Sensitivity or other 
similar constructs. Thus their judgment was based solely on the information they were provided, which made the testing of inter-coder agreement more conservative and is a process recommended by authors in the field of content analysis (Krippendorff, 2003; Holsti, 1969; Stemler, 2001) to prevent the build-up of shared meaning that can occur among experts with specialized knowledge. The average consensus estimate of inter-coder reliability (Stemler, 2004) across all raters and items was $77 \%$ agreement (Cohen's Kappa $=.86$ ), providing reasonably strong evidence supporting the content validity of the instrument.

\section{Criterion-related validity evidence}

The WICS score for the sample was normally distributed $(M=25.42, S D=2.74)$. The correlation between the WICS score and the scores from eight validity measures are shown in Table 5, below. Because the validity measure items often referred to the United States as a home country, six participants who were not U.S. nationals were excluded from the analyses.

As expected, the WICS score was positively correlated with perspective-taking $(r=.25, p<.05)$, empathy $(r=.27, p<.05)$, and internationalism $(r=.39, p<.001)$, and negatively correlated with nationalism $(r=-.36, p<.01)$ and smugness $(r=-.32, p<.01)$. The correlations between the WICS score and openness, patriotism, and ambiguity tolerance were not significant. As indicated by the high mean score of openness $(M=4.27)$, it is possible that the students who participate in study abroad program already are high in openness, thus the magnitude of the correlation between these two variables was likely attenuated due to restricted range and therefore prevented from reaching statistical significance. If a correction for attenuation due to restricted range (Cohen, Cohen, West, \& Aiken, 2003) is applied based on the assumption of a population mean of 3 and standard deviation of .65 for the Openness score, the correlation value becomes statistically significant $(r=$ $.27, p<.05)$. 
Table 5. Means of 8 Validity Measures and Correlation with WICS Score in Part 1 (U.S. national participants only)

\begin{tabular}{l|l|l|l|l|l|l|l|l}
\hline & Openness & $\begin{array}{l}\text { Perspective- } \\
\text { Taking }\end{array}$ & Empathy & Patriotism & Internationalism & Nationalism & Smugness & $\begin{array}{l}\text { Ambiguity } \\
\text { Tolerance }\end{array}$ \\
\hline $\begin{array}{l}\text { Mean } \\
\text { (SD) }\end{array}$ & 4.27 & 3.80 & 3.89 & 3.29 & 3.92 & 1.86 & 1.97 & 10.89 \\
$(.54)$ & $(.60)$ & $(.65)$ & $(.63)$ & $(.69)$ & $(.73)$ & $(.78)$ & $(3.43)$ \\
$\begin{array}{l}\text { Correlation } \\
\text { with WICS } \\
\text { Score }\end{array}$ & .06 & $.25^{*}$ & $.27^{* *}$ & -.09 & $.39^{* \star *}$ & $-.36^{* *}$ & $-.32^{* *}$ & .13 \\
\hline
\end{tabular}

Note. $+p<.10,{ }^{*} p<.05,{ }^{\star \star} p<.01,{ }^{* \star *} p<.001$

\section{Construct-related validity evidence}

In order to examine the construct validity of the scale, the correlations among these six stage scores were analyzed. As Table 6 indicates, overall, the stages that are closer to one another (e.g., denial and defense) showed larger positive correlations, whereas the stages that are more distant from one another (e.g., denial and integration) showed larger negative correlations, indicating that the response items represented well the order of the six developmental stages proposed by Bennett's DMIS.

Table 6. Correlation among 6 Developmental Stages in Part 1

\begin{tabular}{|c|c|c|c|c|c|c|}
\hline & 1 & 2 & 3 & 4 & 5 & 6 \\
\hline Denial & -- & $.47^{\star k+x}$ & $.21^{\star}$ & $-.35^{* \star \star}$ & $-.22^{*}$ & $-.26^{\star \star}$ \\
\hline Defense & & -- & $.18^{+}$ & .06 & .02 & .08 \\
\hline Minimization & & & -- & .12 & $.22^{*}$ & $.23^{*}$ \\
\hline Acceptance & & & & -- & $.42^{\star \star \star *}$ & $.42^{\star * \star}$ \\
\hline Adaptation & & & & & -- & $.70^{\star \star \star}$ \\
\hline Integration & & & & & & -- \\
\hline
\end{tabular}

Note. $+p<.10,{ }^{\star} p<.05,{ }^{\star \star} p<.01,{ }^{\star \star \star} p<.001$

\section{Factors associated with intercultural competency}

In addition to the responses on the WICS and validity measures, we also collected participants' demographic data, their language use during their time abroad, program types, and prior experience 
abroad to discover what factors might be associated with individuals' level of intercultural competence.

Of the 16 situations presented in the instrument, the mean number of situations participants experienced was $11.96(S D=2.45)$, suggesting that the situations were commonly encountered by study abroad students. Not surprisingly, participants who had completed one-semester study-abroad programs $(N=73)$ reported that they encountered significantly more situations $(M=12.45, S D=$ 2.24) than those who had just started their study-abroad program $(\mathrm{N}=24 ; M=10.46, S D=2.50)$, $t(95)=3.67, p<.001, d=.84)$. As shown previously in Table 2 , the majority of participants encountered most of the situations, with the exception of situation 7 (local family party) and situation 14 (religious service). The number of different situations participants had experienced (of the 16 on the test) was significantly positively associated with WICS score $(M=11.96, S D=2.45, r=$ $0.37, p<.001)$, suggesting that the greater the number of situations experienced when studying abroad (e.g., taking local transportation, attending local sporting events), the higher one's intercultural competence score.

In addition, the percentage of time spent speaking the local language (English-speaking countries were excluded) was also significantly positively correlated with the WICS score $(M=$ $45.9 \%, S D=30.5 \%, r=.37, p<.001)$. Finally, female participants $(M=7.88, S D=2.82)$ showed significantly higher intercultural competence than their male counterparts $(M=6.57, S D=2.12$, $t(93)=2.21, p<.03, d=1.86)$. Differences in ethnicity, program type, and participants' prior study abroad experience were not significantly related to differences in intercultural competence.

\section{Part 2: Assessment of changes in intercultural competence}

With the 30 participants who responded to the survey twice, we examined whether the WICS score could capture the changes participants made in their intercultural competence. The length between the two responses ranged between 45 and 185 days $(M=101.87, S D=36.16)$.

As shown in Table 7, below, the WICS score of participants at the end of the study abroad program was significantly higher than at the beginning of the program, indicating that the participants increased their intercultural competence within the short period of time. The effect size was large $(d=.71)$. In contrast, most of the eight validity measure scores showed no significant differences. The only measure other than the WICS that showed significant difference was ambiguity tolerance, with a moderate effect size $(d=.47$, see Table 7$)$.

We also tested whether any available variables (e.g., gender, program type, and prior experience abroad) significantly predicted the size of the change in WICS score. However, none of these 
variables were found to be significant, perhaps due to the small sample size. Although marginally so, the length between Time- 1 and Time- 2 as well as the change in the number of situations experienced between Time- 1 and Time- 2 were positively correlated with the size of change in the WISC score, $r s$ $=.31, .35, p s<.10$. Thus, those who stayed longer and who increased the variability of situations experienced during their program increased their intercultural competence more.

Table 7. Score changes in WICS Score and 8 validity measures in Part $2(\mathrm{~N}=30)$

\begin{tabular}{lllll} 
& Time-1 & Time-2 & Score Change \\
\hline & Mean $(S D)$ & Mean $(S D)$ & Mean $(S D)$ & Effect Size $(d)$ \\
WICS Score & $25.02(2.92)$ & $26.85(2.18)$ & $1.82(2.11)^{\star \star \star}$ & .71 \\
Openness & $4.41(.28)$ & $4.45(.34)$ & $.05(.23)$ & .15 \\
Perspective-Taking & $3.78(.58)$ & $3.78(.56)$ & $.00(.38)$ & .00 \\
Empathy & $3.92(.68)$ & $3.99(.76)$ & $.07(.47)$ & .10 \\
Internationalism & $3.92(.53)$ & $4.11(.69)$ & $.20(.60)$ & .32 \\
Nationalism & $1.86(.46)$ & $1.89(.70)$ & $.03(.58)$ & .05 \\
Smugness & $2.05(.54)$ & $2.06(.61)$ & $.01(.68)$ & .02 \\
Patriotism & $3.29(.46)$ & $3.51(.61)$ & $.23(.48)$ & .42 \\
Ambiguity Tolerance & $10.45(3.02)$ & $11.90(3.21)$ & $1.45(2.39)^{\star}$ & .47 \\
\hline
\end{tabular}

${ }^{*} p<.05,{ }^{* *} p<.01,{ }^{* * *} p<.001$

\section{Discussion}

Higher education institutions, governmental organizations, and private industry all agree that college graduates today must develop intercultural competence in order to understand and adapt successfully to the world. Although the definition of intercultural competence remains somewhat contested, a consensus is beginning to emerge that intercultural competence is a combination of knowledge, skills, and dispositions (Deardorff, 2006). The aim of the current study was to investigate the utility of a new measure of intercultural competence - the WICS - that defines intercultural competence as a skill that develops along a predictable, and theoretically coherent, trajectory. This conceptualization of intercultural competence lends itself well to potential for assessing changes in development that may occur as a result of study-abroad experiences.

The results of the current study suggest that the WICS appears to work very well psychometrically. The WICS is a theory-based instrument with strong evidence supporting its content validity. In addition, the results show that the subscales correlated with regard to adjacent steps, which provides construct validity evidence to indicate that the measure is, in fact, accurately aligned with Bennett's DMIS. Furthermore, the WICS correlates positively with many of the attributes that leading intercultural scholars have identified as central to the definition of intercultural competence (Deardorff, 2006). Specifically, international experts on intercultural competence agree that the ability to take on the perspective of another is a key characteristic of intercultural competence, and the WICS scores correlated significantly positively with a measure of 
perspective taking ability. In addition, the WICS was positively correlated with empathy and internationalism - two other key attributes identified by experts as indicative of intercultural competence. These results provide strong evidence in support of convergent validity. At the same time, WICS scores were negatively correlated with factors that are not supposed to relate to intercultural competence (e.g., smugness, nationalism), showing evidence of discriminant validity. Taken together, these findings provide strong criterion-related validity evidence in support of the fact that the WICS is, in fact, measuring intercultural competence.

Perhaps most significantly, the results of this study show that the WICS is capable of detecting changes in the development of intercultural competence over time. Despite the relatively small sample of individuals completing the instrument on a pre/post basis, the effect size of the change in the development of intercultural competence was rather large $(d=.71)$ and therefore was captured by the WICS. Similar changes were not captured through the use of personality measures (e.g., openness), which is perhaps not altogether surprising. One would not expect a fixed personality trait to change much over time as a result of a cultural immersion experience. Thus, a personality-based approach to measurement may be more useful at the level of selection but less useful as a tool for measuring growth and change over time. Those who go abroad are generally open to experience from the outset and that attitude does not appear to change much as a result of their study abroad experience.

With regard to substantive findings, what is clear from the data is that those participants who experience a wider variety of situations (i.e., breaking out of simply interacting with transportation issues and moving into a space where they are interacting more widely and/or deeply with the host community) tend to score higher on the WICS. These results are consistent with the findings from previous research suggesting that the more exposure students get to a new culture, the more likely they are to learn and develop (Lou \& Bosley, 2008; Savicki \& Selby, 2008). However, the results from our data suggest that it may not be the amount of time that matters so much as the variety of experiences a student encounters that will facilitate the development of intercultural competence.

A second substantive finding from this study is that those students who reported spending a great amount of time speaking a foreign language while abroad tended to score more highly on the WICS. What these data suggest is that those students who embrace the host-country language and immerse themselves in speaking it will be more fully engaged and will develop their intercultural competence at a more rapid rate than those who spend less time speaking the local language. This finding is consistent with much prior research in the area of study abroad (Hoffa, 2010); however, it is all the more interesting in the current context because the WICS items do not ask about time spent speaking the language but rather about how individuals dealt with relatively more and less 
common cultural experiences in their chosen country.

A third substantive finding was that females outperformed males on the WICS, which is consistent with the finding Vande Berg et al. (2009) have reported. While examining the reason for such a gender difference is beyond the scope of the present research, it might be related to the fact that female students are over-represented study-abroad participants in general (Bhandari \& Chow, 2009). For example, it is possible that female students are more interested in and willing to expose themselves to different cultural experiences. This suggests that there might also be gender differences in the development of intercultural competence that warrant further investigation.

\section{Limitations and future directions}

The results from the current study are promising; however, they need to be replicated at a larger scale across a wider variety of students. In addition, the variety of situations encountered is certainly less than exhaustive and could be expanded. Also, it would be worth running future studies to compare the WICS scores to those of the IDI, the Global Perspectives Inventory (GPI) and the $\mathrm{ABOS}$ or other existing measures of intercultural competence for comparative purposes. While the current study provided some preliminary evidence of factors that may predict the development of intercultural competence, future research should aim to obtain more concrete evidence with a larger sample of participants. Finally, students who studied abroad in English speaking countries were excluded from the present study mainly because the small sample size of this group would not have yielded statistically meaningful results; however, an intriguing question worthy of future research is whether these students develop intercultural competence at a rate that is comparable to students in non-English speaking countries.

\section{Conclusion}

Overall, the data from this study suggest that the WICS holds promise as a new tool for measuring the development of intercultural competence as a result of study abroad experiences. The WICS was designed to measure the behavioral element of intercultural competence and may be a useful complement to existing measures of attitudinal and cognitive elements of the construct.

The WICS has several advantages over current measures, both psychometrically and pragmatically. First, it is freely available for use by any institution, provided that it is properly cited and acknowledged. Second, it can be expanded and adapted easily, with new situations being added to the scale, provided they are validated. Third, it is easy to administer and score. Fourth, it is sensitive to developmental changes in intercultural competence even over a relatively brief period of 
time. Fifth, it avoids many of the problems of self-enhancement that plague self-report measures and lead to ceiling effects. Sixth, the WICS would be used not only to evaluate individuals' intercultural competence but also to investigate which elements of study-abroad programs might play a more important role in fostering participants' intercultural competence as well as how participants' personal factors might interact with program characteristics (e.g., perhaps a hybrid program is better for advanced language speakers but an island is better for beginners). Such information would be used to improve existing study-abroad programs re-designing programs as well as helping students to select right programs for them. Finally, the WICS may be useful in a professional development context. For example, the instrument may be used to help students reflect on their responses prior to their study abroad departure as well as using it for debriefing purposes. Used this way, the main purpose of the instrument would not be for selection and for program evaluation, but rather as a useful tool that may help to enhance the development of intercultural competence. In the area of social intelligence, for example, it has been shown that people develop expertise faster when given a theoretical framework for interpreting their responses. Ultimately, we see this new tool as an instrument that is designed both to help and to enhance the development of intercultural competence.

\section{References}

American Council on Education. (2002). Beyond September 11: A comprehensive national policy on international education. Washington, DC: American Council on Education.

Antonio, M.J., Chang, K.H., Kenny, D., Levin, S., \& Milem, J.F. (2003). Effects of racial diversity on complex thinking in college students. Downloaded from: http://siher.stanford.edu/publicationsalphabytitle.html

Association of American Colleges and Universities. (2010). Raising the bar: Employer's views on college learning in the wake of the economic downturn. Washington, DC: Hart Research Associates.

Bennett, M. J. (1986). A developmental approach to training for intercultural sensitivity. International Journal of Intercultural Relations, 10(2), 179-195.

Bhandari, R., \& Chow, P. (2009). Open doors 2009: Report on international educational exchange. New York: Institute of International Education.

Black, J.S. (1990). The relationship of personal characteristics with adjustment of Japanese expatriate managers. Management International Review, 30, 119-134.

Blaich, C., \& Wise, K. (2011). From gathering to using assessment results: Lessons from the Wabash national study. Occassional Paper \#8. University of Illinois: National Institute for Learning Outcome Assessment.

Bond, S. (2003b). Untapped resources: Internationalization of the curriculum and classroom experience: 
A selected literature review (CBIE Research Millennium Series No. 7). Ottawa, ON: Canadian Bureau for International Education.

Braskamp, L.A., Braskamp, D.C., Merrill, K.C., \& Engberg, M. (2011). Global Perspective Inventory (GPI): Its purpose, construction, potential uses, and psychometric characteristics. Downloaded May 29, 2012 from: https://gpi.central.edu/supportDocs/manual.pdf

Byram, M. (1997). Teaching and assessing intercultural communicative competence. Clevedon, UK: Mutlilingual Matters.

Burn, B. (2002). The curriculum as a global domain. Journal of Studies in International Education, 6(3), 253-261.

Caligiuri, P. M., Jacobs, R. R., \& Farr, J. L. (2000). The Attitudinal and Behavioral Openness Scale: Scale development and construct validation. International Journal of Intercultural Relations, 24, 27-46.

Cohen, J., Cohen, P., West, S.G., \& Aiken, L.S. (2003). Applied multiple regression/correlation analysis for the behavioral sciences ( ${ }^{\text {rd }}$ Ed.). Mahwah, NJ: Lawrence Erlbaum Publishers.

Corbitt, J. N. (1998). Global Awareness Profile: GAP facilitator's manual. Yarmouth, ME: Intercultural Press.

Davis, M.H. (1980). A multidimensional approach to individual differences in empathy. JSAS Catalog of Selected Documents in Psychology. Accessed July 22, 2011 from: http://www.uv.es/-friasnav/Davis_1980.pdf

Deardorff, D.K. (2006). Identification and assessment of intercultural competence as a student outcome of internationalization. Journal of Studies in International Education, 10(3), 241-266.

Deardorff, D.K. (Ed.). (2009). The SAGE handbook of intercultural competence. Thousand Oaks, CA: Sage Publications.

DeVellis, R. F. (1991). Scale development: Theory and applications (Vol. 26). Newbury Park, CA: Sage Publications.

Edwards, J., \& Tonkin, H. (1990). Internationalizing the community college: Strategies for the classroom. New Directions for Community Colleges, 70, 17-26.

Engle, L., \& Engle, J. (2004). Assessing language acquisition and intercultural sensitivity development in relation to study abroad program design. Frontiers: The Interdisciplinary Journal of Study Abroad, 10, 253-276.

Fantini, A.E. (2006). Exploring and assessing intercultural competence. Retrieved May 29, 2012 from http://digitalcollections.sit.edu/worldlearning_publications/1/

Goldberg, L. R., Johnson, J. A., Eber, H. W., Hogan, R., Ashton, M. C., Cloninger, C. R., \& Gough, H. C. (2006). The International Personality Item Pool and the future of public-domain personality measures. Journal of Research in Personality, 40, 84-96.

Green, M. F., \& Olson, C. (2003). Internationalizing the campus: A user's guide. Washington, DC: 
American Council on Education.

Gürüz, K. (2011). Higher Education and International Student Mobility in the Global Knowledge Economy (2 $2^{\text {nd }}$ Ed.). Albany, New York: SUNY Press.

Hammer, M. R. (2011). Additional cross-cultural validity testing of the Intercultural Development Inventory. International Journal of Intercultural Relations, 35, 474-487.

Hammer, M. R. (1998). A measure of intercultural sensitivity: The Intercultural Development Inventory. . In S. Fowler \& M. Fowler (Eds.), The intercultural sourcebook (Vol. 2). Yarmouth, ME: Intercultural Press.: Intercultural Press.

Hammer, M. R., Bennett, M. J., \& Wiseman, R. (2003). Measuring intercultural sensitivity: The Intercultural Development Inventory. International Journal of Intercultural Relations: Special Training Issue, 27(4), 421-443.

Hirsch, E. D. (1987). Cultural literacy : what every American needs to know. Boston: Houghton Mifflin.

Hoffa, W.W. (2010). A history of U.S. study abroad: Beginnings to 1965. A special publication of Frontiers: The interdisciplinary journal of study abroad and The forum on education abroad.

Holsti, O.R. (1969). Content analysis for the social sciences and humanities. Reading, MA: AddisonWesley.

Hurtado, S. (2001). Linking diversity and educational purpose: How diversity impacts the classroom environment and student development. In G. Orfield and M. Kurlaender (Eds.), Diversity challenged: Evidence on the impact of affirmative action. Harvard Civil Rights Project.

International Personality Item Pool: A Scientific Collaboratory for the Development of Advanced Measures of Personality Traits and Other Individual Differences (http://ipip.ori.org).

Institute of International Education. (2011). Open doors report 2011. Downloaded May 18, 2012 from http://www.iie.org/en/Research-and-Publications/Open-Doors

Kosterman R., \& Feshbach, S. (1989). Toward a measure of patriotic and nationalistic attitudes. Political Psychology, 10(2), 257-274.

Krippendorff, K. (2003). Content analysis: an introduction to its methodology (2nd Ed.). Newbury Park, CA: Sage.

Kuh, G. (2003). What we're learning about student engagement from NSSE. Change, Mar-Apr., 2432.

Lincoln Commission (2005). Global competence and national needs: One million Americans studying abroad. Final report from the Commission on the Abraham Lincoln Fellowship Program, Washington, DC.

Lou, K., \& Bosley, G. (2008). Dynamics of cultural contexts: Meta-level interventions in the study abroad experience. In V. Savicki (Ed.). Developing intercultural competence and transformation: Theory, research, and applications in international education (pp. 276-296). Sterling, VA: Stylus. 
MacDonald, A. P. (1970). Revised scale for ambiguity tolerance: reliability and validity. Psychological Reports, 26, 791-798.

McDaniel, M. A., \& Nguyen, N. T. (2001). Situational judgment tests: A review of practice and constructs assessed. International Journal of Selection \& Assessment, 9(1-2), 103-113.

Nilsson, B. (2000). Internationalising the curriculum. In P. Crowther, M. Joris, M. Otten, B. Nilsson, H. Teekens, \& B. Wächter (Eds), Internationalisation at home: A position paper (pp. 21 27). Amsterdam: European Association for International Education.

Paige, R.M., Jacobs-Cassuto, M., Yershova, Y.A., \& DeJaeghere, J. (2003). Assessing intercultural sensitivity: An empirical analysis of the Hammer and Bennett Intercultural Development Inventory. International Journal of Intercultural Relations, 27, 467-486.

Salisbury, M.H. (2011). The effect of study abroad on intercultural competence among undergraduate college students. Doctoral dissertation; University of Iowa. Downloaded April 14, 2012 from: http://ir.uiowa.edu/edt/1073.

Savicki, V., \& Selby, R. (2008). Synthesis and conclusions. In V. Savicki (Ed.). Developing intercultural competence and transformation: Theory, research, and applications in international education (pp. 276-296). Sterling, VA: Stylus.

Schapper, J. N., \& Mayson, S. E. (2004). Internationalisation of curricula: An alternative to the Taylorisation of academic work. Journal of Higher Education Policy and Management, 26(2), 189205.

Schuerholz-Lehr, S., Caws, C., van Gyn, G., \& Preece, A. (2007). Internationalizing the higher education curriculum: An emerging model for transforming faculty perspectives. Canadian Journal of Higher Education, 37(1), 67-94.

Sinicrope, C., Norris, J., \& Watanabe, Y. (2007). Understanding and assessing intercultural competence: A summary of theory, research and practice. Second Language Studies, 26(1), 1-58.

Spitzberg, B.H., \& Changnon, G. (2009). Conceptualizing intercultural competence. In D.K. Deardorff (Ed.), The SAGE handbook of intercultural competence (pp. 2-52). Thousand Oaks, CA: Sage publications.

Stemler. S.E. (2004). A comparison of consensus, consistency, and measurement approaches to estimating interrater reliability. Practical Assessment, Research, and Evaluation, 9(4). Retrieved May 31, 2012 from: http://PAREonline.net/getvn.asp?v=9\&n=4

Stemler, S.E. (2012). What should university admissions tests predict? Educational Psychologist, 41(1), 5-17.

Sternberg, R.J. (2004). Culture and intelligence. American psychologist, 59(5), 325-338.

Ting-Toomey, S., \& Kurogia, A. (1998). Facework competence in intercultural conflict: An updated face-negotiation theory. International Journal of Intercultural Relations, 22, 187-25.

Vande Berg, M., Connor-Linton, J., \& Paige, M. R. (2009). The Georgetown Consortium project: 
Interventions for student learning abroad. Frontiers: The Interdisciplinary Journal of International Education, 18, 1-76.

Van de Mortel, T.F. (2008). Faking it: social desirability response bias in self-report research. Australian Journal of Advanced Nursing, 25(4), 40-48.

Weekley, J. A., \& Ployhart, R. E. (Eds.). (2006). Situational judgment tests. Mahwah, NJ: Lawrence Erlbaum Associates, Inc. 


\title{
APPENDIX:The Wesleyan Intercultural Competence Scale (WICS)
}

\author{
Steven Stemler, Toshie Imada, Carolyn Sorkin \\ Wesleyan University
}

Instructions: This test presents 16 different situations that study abroad students are likely to encounter. For each situation, six different responses are presented. Please think of the most recent time that you encountered each situation while you were studying abroad and choose a number (1=Very Inaccurate, 5=Very Accurate) to indicate the degree to which each response fits your actual behaviors and thoughts at that time. If you did not encounter one of the situations, please skip the table of responses and simply check the box that says "I did not encounter such a situation."

Very Inaccurate 1
2
3
Very Accurate 5

\section{Situation 1: When I used local public transportation,}

1. __ I I asked friends, family, and local people for help in navigating the transportation system and tried to use it whenever I went out.

2. __ I I became comfortable relying upon it on a daily basis and enjoyed using the system to get around to places.

3. _ _ I thought that the country needed to improve their system and make it easier for foreigners to use, such as having clear signs in English.

4. _ _ I told myself that public transportation in the US is not that great either, but that there were always other ways to get around.

5. _ _ I tried to remember that many people in this country had figured it out and that I would too, as well, if I just keep trying to get the hang of it.

6. __ i it was a rare occasion. I tried to avoid taking the public transportation and didn't travel too much.

7. __ I I did not encounter such a situation. 


\begin{tabular}{|ccccc|}
\hline Very Inaccurate & & & & Very Accurate \\
1 & 2 & 3 & 4 & 5 \\
\hline
\end{tabular}

\section{Situation 2: When I was interacting with local peers,}

1. _ _ I became more sensitive to subtle cues that they would give to indicate their thoughts and feelings.

2. _ _ I f found that they were very much like my friends in the US.

3. _ t their reactions were a bit different from the ones I get from my US peers, but perhaps it was just because I didn't speak the language well.

4. __ noticed that they didn't enjoy talking about certain topics that I usually talk about with friends in the US, so I tried not to bring up those topics.

5. _ _ I sometimes felt that they didn't understand my jokes, and I felt I could not really connect with them. I guess they weren't really worldly enough to understand different points of view.

6. _ _ they sometimes did not react in the ways I expected, which surprised me, but also made me curious why that was.

7. ___ I did not encounter such a situation.

\section{Situation 3: When I went out with others,}

1. __ I tried to go out with local peers rather than US peers, so I could learn more about the local cultures.

2. __ I usually hung out with others who were also from the US because I felt comfortable being with them.

3. __ I I went out with local peers as much as my US peers. Although there were sometimes communication barriers, we were all college students and enjoyed having fun so it didn't matter.

4. __ I went out with local peers a lot, and we became very good friends and enjoyed doing things together.

5. _ _ I sometimes went out with local peers, but I felt that they were kind of aloof and not as friendly as Americans.

6. _ _ I went out with local peers a lot, and as a result became more open-minded in terms of interacting with people with diverse backgrounds, ideas, and preferences, whether they were from my own culture or not.

7. ___ I did not encounter such a situation. 


\begin{tabular}{|ccccc|}
\hline Very Inaccurate & & & & Very Accurate \\
1 & 2 & 3 & 4 & 5 \\
\hline
\end{tabular}

\section{Situation 4: When visiting a local landmark,}

1. _ _ I went for a trip whenever there was an opportunity, as taking a trip is always fun anywhere.

2. _ _ I wasn't all that interested in exploring the local landmarks, so unless there was a trip offered/required by the program, I wasn’t really eager to visit anywhere else.

3. __ it was sometimes challenging for me to figure out things like transportation system and directions, but I thought of it as an exciting part of the cultural experience.

4. _ _ I participated in a tour (or tours) for Americans, because I thought it would be cleaner, more efficient, and more enjoyable.

5. _ _ I traveled both in and out of the country, with both US friends and local friends who were interested in traveling. I took several short trips as well as at least one longer (e.g., weeklong) trip as well.

6. _ I I planned and went on a trip by myself as I felt pretty comfortable with the area. Even when some unexpected things happened (e.g., bus did not come), I found a way to manage and enjoy the trip.

7. __ I I did not encounter such a situation.

\section{Situation 5: When I went grocery shopping,}

1. _ _ I just got the things that were usually sold in the US because I was afraid of wasting money for something terrible.

2. _ _ I found that the stores were pretty much like the ones in the US, and I did not find any big differences. Grocery stores are just grocery stores anywhere.

3. _ I I enjoyed finding things that I never saw in the US and I was curious about what they were.

4. __ I I tried to go shopping with other Americans or find a store that catered to Americans

5. _ _ I bought and tried local products and discovered really good ones. So I became more openminded and less restricted by familiarity and brand names when choosing right products for myself.

6. _ _ I often bought local products that were a little different from the products I get in the US and I used them a lot in my everyday living.

7. __ I I did not encounter such a situation. 


\begin{tabular}{|ccccc|}
\hline Very Inaccurate & & & & Very Accurate \\
1 & 2 & 3 & 4 & 5 \\
\hline
\end{tabular}

\section{Situation 6: When I could not find something I needed, which I could usually get easily in the US (e.g., products, services, etc.),}

1. __ it was a good opportunity to realize that we take so many things for granted and do not appreciate it enough.

2. __ I thought that I was much better off living in my own country.

3. _ _ I simply gave up and tried not to think about it. It wasn't a big deal any way.

4. _ I I asked people around and found an alternative that was available in the country and used that instead.

5. _ I I was surprised but also curious why it was not common in this country.

6. _ I was frustrated and disappointed with the fact that this country did not even have such a basic thing.

7. __ I did not encounter such a situation.

\section{Situation 7: When I was exposed to local media coverage (e.g. radio, TV, newspapers),}

1. _ I I paid a little bit of attention to what was being said, but I was most interested in hearing about news that was related to the US because that's more important.

2. _ I I listened to the news and read about local affairs because it helped me carry out conversation with local people.

3. _ I t thought that the same problems were prevalent in any society - unemployment, socioeconomic disparities, violence and crimes, etc.

4. _ It was interesting to hear them talk about the local government and other things going on in the area as I did not know much about them.

5. _ I I enjoyed finding out that the same incidents could be given different weight and viewed very differently in different countries, which broadened my perspectives for public affairs in general.

6. __ I didn't bother paying attention since it was all about local affairs.

7. __ I did not encounter such a situation. 


\begin{tabular}{|ccccc|}
\hline Very Inaccurate & & & & Very Accurate \\
1 & 2 & 3 & 4 & 5 \\
\hline
\end{tabular}

\section{Situation 8: When a local peer expressed views that were different from my own (e.g., political opinions, values),}

1. _ I I tried to understand her/his opinion and, as a result, became more supportive of her/his view.

2. __ I thought that his/her view was sort of rigid and lacked openness.

3. _ I I was curious about why s/he thought that way and wanted to know more about it.

4. _ _ I thought that different opinions, including mine, were equally valuable, and I was able to understand different views from an objective standpoint without being judgmental about which was right or wrong.

5. _ _ I thought that whatever his/her views were like, it was great that s/he shared them with me. After all, everyone has different opinions about everything.

6. _ I I stopped paying attention, as I wasn't comfortable talking to someone who did not share the same opinion as mine.

7. __ I did not encounter such a situation.

Situation 9: When I ate a local cuisine that tasted really strange,

1. __ I couldn't believe how people in this country could enjoy such a terrible thing.

2. _ I I thought it would be safer for me to stick to American foods from now on and avoid eating local cuisine.

3. _ _ I thought I should try eating it since eating different food is a part of cultural experience.

4. _ I I didn't hesitate to eat it because I believed that trying various types of foods would broaden my attitudes towards any types of cuisines and enrich my life in general.

5. _ I I tried it several more times to see whether I might come to like it.

6. _ I I realized that there are things that I don't like in the US, too. So if I didn't like it, I just didn't eat it.

7. _ _ I did not encounter such a situation. 


\begin{tabular}{|ccccc|}
\hline Very Inaccurate & & & & Very Accurate \\
1 & 2 & 3 & 4 & 5 \\
\hline
\end{tabular}

\section{Situation 10: When I was invited to a formal dinner,}

1. __ it was awkward because the food and/or table manners were so bizarre.

2. _ _ the food and manners were quite different from the ones in the US, and that fascinated me.

3. _ I I felt comfortable trying/ eating most of the food in culturally appropriate ways without making conscious effort, and I actually enjoyed it.

4. _ I I behaved as I do in the US, because I found the manners and foods are pretty much the same as the ones we have in the US.

5. _ I I was curious and tried to learn what the types of food were and how I should eat them in order to more fully enjoy the experience.

6. _ _ I found that the food and manners were a bit different from the ones in the US but ultimately such differences are trivial because we all enjoy eating good food.

7. __ I did not encounter such a situation.

Situation 11: When a local person did not understand what I said in the local language and seemed to be a bit frustrated or confused,

1. __ I was disappointed with my language skills and became aware that speaking a foreign language like natives was a difficult task to accomplish.

2. _ _ I felt sorry that I made her/him uncomfortable and realized that I should be more respectful to people who are attempting to speak in a language that is not native to them.

3. _ I I soon gave up talking to him/her, and looked for someone who looked like an American so I could communicate in English.

4. _ _ I thought to myself, it's normal that people have difficulty communicating in foreign languages, so I didn't take it seriously, just smiled, and let him/her go.

5. _ I I tried to speak slowly and clearly, showing my willingness to communicate with him/her.

6. _ I I thought s/he should be more patient and sympathetic to me. After all, I was trying to communicate in their language, not in English.

7. _ I I did not encounter such a situation. 


\section{Very Inaccurate 12 \\ $3 \quad 4$ \\ Very Accurate 5}

Situation 12: When I was interacting with a professor (or a supervisor) in a culture where respecting someone with higher status was considered to be very important,

1. _ I f felt that s/he was distant, but perhaps that's because we did not spend enough time together to get to know each other.

2. ___ to show my respect, I carefully chose my words as to not be too friendly or too confident.

3. _ I sometimes felt that s/he was treating me as inferior. I found this annoying because American professors (or supervisors) would not treat me like that.

4. __ I admired such cultural values and practices although it made me feel a little uncomfortable.

5. ___ Depending on the person with whom I interacted, I adapted my behavior. So when I interacted with a person with higher status, I naturally acted in a more polite and humble manner without having to think too much about it.

6. __ I interacted with her/him as I do with my friends because I think it is important to interact with all people the same regardless of their status, and I did not see anything wrong with it.

7. _ I I did not encounter such a situation.

Situation 13: When I went to a local cultural event (e.g., a play, concert, sports game, etc) with local peers,

1. _ I I did not enjoy it as much as I thought I would, but then again I sometimes felt uncomfortable at big events like this in the US as well, so maybe it just has to do with my personal preference, not the event itself.

2. _ I I was very bored as I couldn't understand what was going on. I wished that I had gone to an event I was more familiar with, like a movie or a baseball game.

3. __ even though it was different from my usual experience, I enjoyed seeing the event and how my local peers behaved when going out.

4. _ I l loved it. I often went to events like this with locals and enjoyed them very much. I intend to pursue more opportunities to go out to events that I have never been to before once I return to the U.S.

5. __ I had a great time going to an event like this, and it also gave me an opportunity to get to know my local peers a little better.

6. _ I couldn't understand what was going on because it was in a different language, and I was frustrated that they did not translate things into English.

7. _ _ I did not encounter such a situation. 


$\begin{array}{ccccc}\text { Very Inaccurate } & & & & \text { Very Accurate } \\ 1 & 2 & 3 & 4 & 5\end{array}$

\section{Situation 14: When I participated in discussions with other local peers, and others seemed to be rather quiet,}

1. __ I thought that since others were not willing to share their opinions, I wasn't willing to share mine either.

2. _ _ I was aware that their communication styles and cultural emphasis on group harmony were different than in the US, so, whenever I expressed my opinions, I did so in an indirect or suggestive way and responded positively to what others said.

3. _ I thought that it was probably because the topic wasn’t interesting enough.

4. _ I thought that it was perhaps due to their cultural emphasis on group harmony, and I respected their values.

5. _ _ I felt that they were too shy and should express their opinions more freely, like Americans do.

6. _ _ I took it as a sign that they might not be comfortable expressing their opinions so I did not push the matter like I might have in the US. I felt that maintaining group harmony was more important than having a heated discussion, so I tried to refrain from expressing my opinions to fit in with the group.

7. __ I did not encounter such a situation.

\section{Situation 15: When I was invited to a local family party and I was not sure how formal it was,}

1. __ I anticipated that that I might be a bit off from the standard of others since the dress code was a bit more strict in this culture than in the US.

2. I I didn't pay much attention to what I should wear.

3. __ I was worried about dressing appropriately because I felt that doing so would be a sign of respect and appreciation toward the host. From my past experience, I knew what the appropriate clothing would be for this situation and I carefully made a right choice.

4. __ people would wear different things anyway, so I thought that as long as I showed up, what I would wear wouldn't be so important.

5. __ I asked others what I should wear because I did not want the family who invited me to be embarrassed in front of other guests if I did not dress appropriately.

6. _ I I wore the clothes that I liked, because I did not want to change who I was.

7. __ I did not encounter such a situation. 


\begin{tabular}{|ccccc|}
\hline Very Inaccurate & & & & Very Accurate \\
1 & 2 & 3 & 4 & 5 \\
\hline
\end{tabular}

\section{Situation 16: When I went to a religious service or event that differed from my own religious beliefs,}

1. _ I I was curious to know what it would be like and how different it would be in comparison to what I was familiar with.

2. _ _ I enjoyed listening to the service and learning what the religion was about, because it made me realize the impact of religion on people's daily practices, beliefs, and values, including my own.

3. _ I I realized that the ways people practice religion might be different, but many people in the world believe in God.

4. __ it made me very uncomfortable so I just tried to attend services of my own religion, with which I was familiar.

5. _ _ it seemed rather weird and primitive, and I didn't understand why the people there believed in such a strange religion.

6. __ although it wasn't the religion I personally believed, attending the service made me feel like I was a part of the community.

7. __ I did not encounter such a situation. 


\section{Scoring Key}


Situation 1
1. ADAPTATION
2. INTEGRATION
3. DEFENSE
4. MINIMIZATION
5. ACCEPTANCE
6. DENIAL

Situation 2
1. INTEGRATION
2. DENIAL
3. MINIMIZATION
4. ADAPTATION
5. DEFENSE
6. ACCEPTANCE

Situation 3
1. ACCEPTANCE
2. MINIMIZATION
3. DENIAL
4. ADAPTATION
5. DEFENSE
6. INTEGRATION

Situation 4

1. MINIMIZATION

2. DENIAL

3. ACCEPTANCE

4. DEFENSE

5. INTEGRATION

6. ADAPTATION

Situation 5

1. DEFENSE

2. MINIMIZATION

3. ACCEPTANCE

4. DENIAL

5. INTEGRATION

6. ADAPTATION

Situation 6

1. INTEGRATION

2. DENIAL

3. MINIMIZATION

4. ADAPTATION

5. ACCEPTANCE

6. DEFENSE
Situation 7

1. DEFENSE

2. ADAPTATION

3. MINIMIZATION

4. ACCEPTANCE

5. INTEGRATION

6. DENIAL

Situation 8

1. ADAPTATION

2. DEFENSE

3. ACCEPTANCE

4. INTEGRATION

5. MINIMIZATION

6. DENIAL

Situation 9

1. DEFENSE

2. DENIAL

3. ACCEPTANCE

4. INTEGRATION

5. ADAPTATION

6. MINIMIZATION

Situation 10

1. DEFENSE

2. ACCEPTANCE

3. INTEGRATION

4. DENIAL

5. ADAPTATION

6. MINIMIZATION

Situation 11

1. ACCEPTANCE

2. INTEGRATION

3. DENIAL

4. MINIMIZATION

5. ADAPTATION

6. DEFENSE

Situation 12

1. MINIMIZATION

2. ADAPTATION

3. DEFENSE

4. ACCEPTANCE

5. INTEGRATION

6. DENIAL
Situation 13

1. MINIMIZATION

2. DENIAL

3. ACCEPTANCE

4. INTEGRATION

5. ADAPTATION

6. DEFENSE

Situation 14

1. DENIAL

2. INTEGRATION

3. MINIMIZATION

4. ACCEPTANCE

5. DEFENSE

6. ADAPTATION

Situation 15

1. ACCEPTANCE

2. DENIAL

3. INTEGRATION

4. MINIMIZATION

5. ADAPTATION

6. DEFENSE

Situation 16

1. ACCEPTANCE

2. INTEGRATION

3. MINIMIZATION

4. DENIAL

5. DEFENSE

6. ADAPTATION 